THE INTERNATIONAL

REVIEW OF RESEARCH IN

OPEN AND DISTANCE LEARNING

\title{
Connectivism and Dimensions of Individual Experience
}

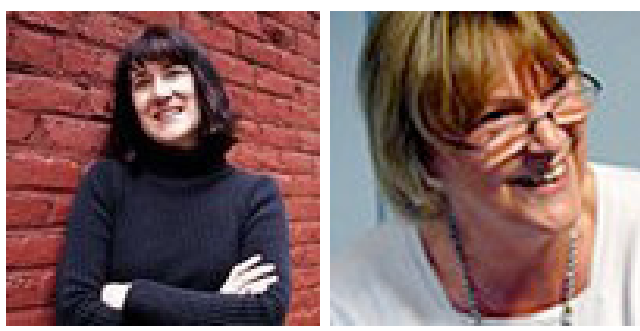

Carmen Tschofen and Jenny Mackness

\section{Abstract}

Connectivism has been offered as a new learning theory for a digital age, with four key principles for learning: autonomy, connectedness, diversity, and openness. The testing ground for this theory has been massive open online courses (MOOCs). As the number of MOOC offerings increases, interest in how people interact and develop as individual learners in these complex, diverse, and distributed environments is growing. In their work in these environments the authors have observed a growing tension between the elements of connectivity believed to be necessary for effective learning and the variety of individual perspectives both revealed and concealed during interactions with these elements. In this paper we draw on personality and self-determination theories to gain insight into the dimensions of individual experience in connective environments and to further explore the meaning of autonomy, connectedness, diversity, and openness. The authors suggest that definitions of all four principles can be expanded to recognize individual and psychological diversity within connective environments. They also suggest that such expanded definitions have implications for learners' experiences of MOOCs, recognizing that learners may vary greatly in their desire for and interpretation of connectivity, autonomy, openness, and diversity.

Keywords: Autonomy; openness; diversity; connectedness; connectivism; self-determination; massive open online course; motivation; personality theory; MOOC; identity; learner experience

\section{Introduction}

Connectivism has been offered, but has not yet been universally accepted, as a new learning theory for a digital age (Verhagen, 2006; Kop \& Hill, 2008; Bell, 2011). For the purposes of this discussion, connectivism is viewed as a viable description of learning that incorporates emergent disciplinary and interdisciplinary understandings that may not yet have been 
tested in traditional forms. It reflects the many shifts in contemporary cultural narrative including increased recognition of systems, complexity, and interrelatedness. Connectivism is based on the principle that all learning starts with a connection (Siemens, 2004). These connections occur on neural, conceptual, and social levels (Siemens, 2008), and in connectivism, learning is thought to be "the ability to construct and traverse connections" (Downes, 2007).

Learning in connectivism terms is a network phenomenon, influenced, aided, and enhanced by socialisation, technology, diversity, strength of ties, and context of occurrence. However, the influences on connectivism that we will focus on in this paper are the four key principles for learning that exist within connectivist thought: autonomy, connectedness, diversity, and openness (Downes, 2010a). Connectivism is a response to a perceived increasing need to derive and express meaning, and gain and share knowledge. This is promoted through externalisation and the recognition and interpretation of patterns, which are shaped by complex networks (both internal neural networks and external social networks) (Siemens, 2004). Connectivism attempts to situate learning in the continual expansion and creation of knowledge and posits that information and knowledge growth in this digital age exceed our ability to cope; the quantity and complexity of information available is overwhelming (Siemens, 2006).

Whilst connectivism has recently been acknowledged as "beginning with the individual," and as "leaving space for human agency" (Bell, 2011), as well as "increasing the value of the individual" (Siemens, 2011), there has been a much more intense focus on the networked and shared (or sharing) experiences that have been viewed as a key difference from other learning theories. An understanding of the individual in connectivism, while acknowledged with respect to the choice and use of technologies associated with personal learning environments and the activities of aggregating, remixing, repurposing, and sharing (Kop \& Fournier, 2010), has not been explored in any detail to this point. It is easy to see that attention to the perspective of the individual may perhaps be viewed as ultimately moot within the cumulative mass of network connections. Additionally, increased attention to the idea of "combinatorial creativity" (a term coined by blogger Maria Popova at http:// www.brainpickings.org/index.php/2011/08/01/networked-knowledge-combinatorial-creativity/), which counteracts the "lone genius" concept with a recognition of the complexity of influences on ideas and creativity (Sawyer, 2007), steers us towards a more collective understanding of learning, creation, and innovation. However the authors suggest that there is still room for - and a need for - both recognition of the accruing and beneficial nature of networked learning and attention to the unique individual as a separate self within the connectivism dialogue.

The discussion here is not intended to "roll back" cultural narrative to reassert the primacy of the individual. It does, however, attempt to understand the interplay between individuals and connectivist thought by introducing the potential perspectives brought by the individual and juxtaposing them with connectivist principles.

An important factor in our understanding is that the testing ground for connectivism and 
its principles has been in massive open online courses (MOOCs). In 2011 we have seen a surge of MOOC offerings (see Wikipedia, Massive Open Online Course for a list of MOOCs - http://en.wikipedia.org/wiki/Massive open online course). MOOCs are online courses that attract a wide diversity of participants from across the world. They are massive in the sense that they can attract literally thousands of participants. They are open in the sense that they are free and participants are expected to openly share their expertise, knowledge, understanding, and ideas, so that knowledge is not only freely distributed across the network, but also created within the network. MOOCs are courses in that they provide a structured curriculum around a given theme or topic, but learners are expected to be autonomous and manage their own learning by making their own social and conceptual connections to suit their own needs.

As the number of MOOC offerings increases, so does awareness of areas of tension as these "events" negotiate between innovative and traditional learning processes. Among those tensions that have recently come to the fore is the desire by some to define a MOOC, and subsequently what is not a "true" MOOC, evidenced by debates surrounding what is truly an "open" course, for example, or the increasingly difficult and limiting distinction between online and offline networks. (See discussions in Change MOOC - $\underline{\text { http://change.mooc.ca/.) }}$ At the same time, an interest in defining acceptable or appropriate roles for individuals within MOOCs and among connectivist participants has arisen. Siemens (2010), for example, has expressed serious reservations about "lurkers," while others have been recently concerned with the "responsibility" of MOOC conveners. In many conversations we detect a tacit conceptual conflation of connectivism and MOOCs.

It should be noted that the discussion offered here is an outgrowth of the ongoing conversations surrounding connectivism in the past several years, during which both authors have participated in varying levels with MOOCs and in applying connectivist principles in their respective environments. It also reflects an effort to gain insight into the actions (or nonactions) and subsequent frustrations evidenced by individual participants in the MOOC environments. The intent is to potentially ease the tensions suggested by the desire for definitions and roles - and the concern about what is the "right way" to "do" connectivism. The process offered here juxtaposes connectivist principles with a basic review of contemporary psychological theory and offers an expanded vocabulary and dialogue surrounding personal motivation and personal choice within connectivist learning and the "testing environment" of MOOCs.

\section{Juxtaposing Three Concepts}

To date, connectivism has been discussed principally in relation to behaviourism, cognitivism, and constructivism (Siemens, 2004; Anderson \& Dron, 2011). In this paper we explore connectivism in relation to personality theory and self-determination theory and suggest that together these three concepts offer a lens through which we can explore dimensions of individual experience in connectivism. 
Stephen Downes has identified autonomy, connectedness, diversity, and openness as the key components of connectivism conducive to (or required for) learning in networks. These descriptors are intended to apply to a network and its functioning and are viewed as positive or desirable conditions, although this was critiqued by Mackness, Mak, and Williams (2010) following their experience of the Connectivism and Connective Knowledge MOOC in 2008 (CCKo8). While recognizing that terms used in one field can have completely unrelated meanings and implications in another discipline, the overlap in language between the concept of connectivist principles and two additional concepts, personality theory and self-determination theory, seems to call for exploration.

\section{A Brief Introduction to Personality Theory}

When psychologists use the term personality, they are referring to the unique and relatively enduring set of behaviors, feelings, thoughts, and motives that characterize an individual...personality is what distinguishes us from one another and makes us unique... personality is relatively enduring, or consistent. (Feist, 2010. p.114)

One of the most widely accepted models of personality traits in contemporary human psychology is the "Big Five" (McCrae \& Costa, 1987). (For a more thorough discussion of the multiple contributors to the evolution of research in personality structures, see John \& Srivastava, 1999).

These five, very broad, spectrum-oriented traits are openness, conscientiousness, extraversion, agreeableness, and neuroticism. Ongoing research in this area also recognizes the situational or environmental factors involved in their expression, as well as the role of biology, evolution, and neuroscience in contributing further understanding of personality traits (Fiest, 2010). John and Srivastava (1999) note:

Personality traits are basic tendencies that refer to the abstract underlying potentials of the individual, whereas attitudes, roles, relationships, and goals are characteristic adaptations that reflect the interactions between basic tendencies and environmental demands accumulated over time. According to McCrae and Costa, basic tendencies remain stable across the life course whereas characteristic adaptations can undergo considerable change.

While it is clear that this is a complex realm of understanding, the simplifying terms of the Big Five allows an initial juxtaposition of personality traits with the networked learning principles, contributing to some interesting relationships. 


\section{A Brief Introduction to Self-Determination Theory}

An additional concept, self-determination theory, has also offered insight into potential relationships between networked learning and individuals within networks. (We acknowledge that this can also include nonhuman nodes, but this is not addressed here). This is not to be confused with self-directed learning, which is oriented toward academic tasks and practice. Kirwan, Lounsbury, and Gibson (2010, p. 23) characterize self-direction as
a personality construct reflecting an individual's preference to be in charge of their learning process; ability to conceptualize, plan, implement, and evaluate their academic experience; and disposition to be goal- oriented and to work independently or in group settings with little guidance.

In contrast, self-determination theory (SDT) examines human growth and initiative as a form of dynamic potential and is closely linked to understandings of psychology and motivation. It is about a 'way of being.'

SDT begins with the belief in and acceptance of innate, constructive tendencies for action and growth (not a universally accepted stance), whilst simultaneously recognizing that complex social-contextual factors affect any potential expression of "integrating" tendencies. Ryan and Deci (2002) introduce three essential components in self-determination: competence, relatedness, and autonomy. All elements, we suggest, are significantly related to the interactions of connectivist learning and connectivist principles, both in terms of gaining a broader understanding of the vocabulary and semantic nuances of terms used to explain connectivism and in understanding factors that affect how and why individuals may choose to engage with connectivist learning.

The discussion here uses the scaffold of the four connectivism principles to explore connections between connectivism, personality theory, and self-determination theory.

\section{Exploring Autonomy}

\section{Autonomy as Choice and Control}

The idea of autonomy is closely identified in educational literature with concepts of choice, control, and independence (see for example Thanasoulas, 2002 and Crome, Farrar, \& O'Connor, 2011). And yet the ability to act independently and select levels of choice and control is not an element that has offered an easy path in connectivist learning, where learners are expected to choose among connections and information, and where deliberate attempts are made to reduce external control by minimizing traditional instructional processes and power structures. In his work on adult learning in formal and semiformal e-learning courses, Dron (2007) has recognized that how autonomy is experienced "varies from person to person and context to context... Different structures will lead, inevitably, 
to different consequences and offer different benefits to different learners." (p. xvi.) He recommends that learners should be able to "choose when to choose," understanding that some learners will opt for more structure (control) or dialogue (choice). Even at this point, "The mediation of learner control requires metacognitive skills that are not universally distributed among the population." (Bouchard, 2011, p. 293).

Along these lines, there have been increasing suggestions that a potentially unfettered network environment may work best only for adults or the most experienced learners and perhaps those with a large amount of traditional education as a background. Some have expressed surprise at the "learned helplessness" of even mature or "well educated" learners, and learners themselves are often frustrated at the lack of control in connectivist environments. In research (Mackness, Mak, \& Williams, 2010) in which participants were surveyed and interviewed about their experience of participation on the massive open online course CCKo8 (Connectivism and Connective Knowledge, 2008), course participants were asked questions designed to elicit their experience of learner autonomy. These questions typically led to the following type of response:

A controlled environment would have been a great start. I liked that participants could start threads of their own but it also got out of hand a few times. It was clear the kids were in control of the classroom, which as an 'experiment' it was sort of expected to be. (Mackness, Mak, \& Williams, 2010, p. 271).

Also: "I felt like some guidance would have helped. Freedom is great, but this course was all over the place. There was no one place to follow the latest thinking on any one subject." (Mackness, Mak, \& Williams, 2010, p. 269).

\section{Psychological Autonomy and the Individual}

Concerns about how or whether learners are motivated or equipped to take advantage of the many options in connectivist environments has engendered some frustration for both learners and facilitators. Some insight may be gained by an understanding of psychological autonomy, which Dron recognizes as different from the autonomy of choice and control (2007, p. 60).

The definition of psychological autonomy offered by Ryan and Deci (2002) seems of interest: “[A]utonomy refers to being the perceived origin or source of one's own behavior. Autonomy concerns acting from interest and integrated values. When autonomous, individuals experience their behavior as an expression of the self...” (p. 8).

In contrast to the potential of connectivist learning, traditional learning environments rarely request or allow an "expression of the self," focusing, rather, on expressions desired by instructors, who have also traditionally determined the scope of choices and learner control. In this light, connectivist environments such as MOOCs may well be placing learners in two dimensions of unfamiliar autonomy, those of both "choice and control," and 
psychological autonomy.

At the same time, while seeing autonomy as an expression of the self, Ryan and Deci (2002) see no contradiction in maintaining a community orientation.

Autonomy is often confused with, or melded together with, the quite different concept of independence (which means not relying on external sources or influence)... Indeed, one can quite autonomously enact values and behaviors that others have requested or forwarded, provided that one congruently endorses them. (p. 8)

Stephen Downes has blogged about autonomy from various angles (see for example, 2010b), and, while often emphasizing a connectivist, network orientation, has also provided descriptions of autonomy that seem to "leave room for" acknowledgment of the individual.

Wherever possible, learners should be guided, and able to guide themselves, according to their own goals, purposes, objectives or values. It is a recognition that, insofar as a person shares values with other members of a community, and associates with those members, it is a sharing freely undertaken, of their own volition, based on the evidence, reason and beliefs they find appropriate.

(Downes, 2010a)

The parallels between these descriptions of autonomy suggest that both the network (or community) autonomy (Downes, 2010a) and autonomy of the self or individual (Ryan \& Deci, 2002) have room for equal focus within connectivism.

\section{Autonomy and Lurking}

Additionally relevant for connective learning is the proposal that while autonomy as choice and control offers a "menu" of externalized actions, autonomy as an expression of the self offers the basis of a rationale or understanding of the motivations involved in making those choices. Reconciling the apparent discrepancy between, for example, outwardly active participation and so-called lurking may well lie in the meshing of an understanding of these two ideas. We suggest that thinking about networked autonomy in terms of choice and control offers the active "what" of learning; thinking about autonomy in terms of self underlies the motivational "why" in accepting or engaging (or not) with those choices.

The current tensions about autonomy and the self or individual in connectivism may also be seen in contrasting two further discussions. Aviram and Assor (2010) introduce the characteristics of an autonomous individual, noting commitment to three values and the ability to realize them: self-knowledge, self-direction, self-expression (p. 118). Yet within connectivism, the modifier "self" is sometimes identified in a negative light. Siemens (2010), a primary connectivism theorist, writes of lurking: 
Being connected, without creating and contributing, is a self-focused, self-centered state.... there is never a good time to be a lurker. Lurking = taking. The concept of legitimate peripheral participation ... is actually negative. Even when we are newcomers in a network or community, we should be creating and sharing our growing understanding...

Siemens is an influential blogger and discussions in the blogosphere have indicated that this is not an uncommon view, where lurking has been referred to as 'free-riding' by a number of authors (see for example Wellman \& Gulia, 1998).

A concern with this view is that there are many extrinsic (community-oriented) and intrinsic (self-oriented) variables among the complex sociocontextual factors, which Ryan and Deci (2002) identify as important to self-determination. Similarly, as suggested here, there are different dimensions of autonomy involved in choosing to participate in obvious and visible ways. With this understanding, the interpretation of certain types of participation (or perceived nonparticipation) as selfishness and the denial of community values seems to reflect a personal worldview and may fail to acknowledge the complexity of individuals engaged in connective spaces.

\section{Exploring Connectedness/Interactivity}

The concern about lurking is also reflected in our exploration of the implications and dimensions of connectedness and interactivity as a connectivist principle. Our experiences as MOOC participants suggest that for some learners there may be a tension between being sufficiently connected to take advantage of all the Web has to offer and having enough choice in relation to 'space' for individual and independent development and personal learning.

\section{Relatedness, Agreeableness, and Neuroticism}

Recent research into personal learning environments, a primary conduit for connectivist learning, has largely discussed connectedness in connectivism in technology-based terms - a collection of hardware and software applications (Cormier, 2011). At the same time, the "sharing" emphasis in connectivism (Kop, 2011) has been linked with a tacit or even explicit expectation of mutual obligation and support, as in Siemens' quote about lurking (2010). Under the vocabulary offered in self-determination theory, we see the networked learning principles of connectedness and interactivity as having parallels in the concept of relatedness (Ryan \& Deci, 2002), which is defined as a sense of personal connectedness, caring, and belonging. These areas of "caring and belonging" take us well into an emotional realm not part of the connectivist conversation to date. One exception is Kop and Fournier's (2010) survey on self-directed learning in open networked environments which suggests that for many learners, the sociality and personal sense of connectedness - relatedness - in networked learning is as valued as the conceptual connections of connectivism. 
This is a delicate and complex area of understanding as there is both the understanding that network participation should be voluntary and not emotionally coercive, while at the same time the tools and technologies used in connective learning are designed as amplifications of human interaction as "social" media. In terms of personality theory, the trait of agreeableness, understood as the tendency to be compassionate and cooperative, may also play a factor here; in the case of digital connectivism, the ability to project agreeableness in an online environment may in part determine perceptions of connectedness, interactivity, and relatedness.

At the same time, the trait of neuroticism, in which individuals may more readily experience negative emotions, may affect perceptions of interactions within networked environments. The presence of a "troll" in the CCKo8 forums, for example, evoked varying expressions of anger and discomfort among some learners and was considered a determining factor in participation levels in that environment (Mackness, Mak, \& Williams, 2010).

\section{Identity, Extraversion, and Introversion}

Etienne Wenger (2011) has reflected that in the 21st century identity can be linked to a multitude of communities (or networks). The challenge for individuals is how to engage with and enable individual identity to be realised in these communities and networks. Wenger's work posits that the definition of identity and the development of relatedness are shifting more and more onto the shoulders of the individual person rather than being automatically acquired through familial, geographic, or other traditional structures.

The shifts in the sources of identity and thus potential relatedness in communities and networks has drawn attention to the idea of the quality of one's network and connectedness/interactivity. At the same time, the very idea of a MOOC is rooted in the idea that the potential quantity of connections, or at least connective opportunities, is a key element of learning.

The personality traits of extraversion and introversion, which affect perceptions of the quality and quantity of personal interactions, may complicate conceptualizations of both quality and quantity in connectedness and interactivity (Topi, Valacich, \& Rao, 2002). These Jungian terms reflect the spectrum along which people are drawn to and gain energy from interactions with other people or from ideas and self-reflection. It may be that these concepts are already embedded in the "layers" of connectivism, perhaps with the "social" layer accommodating varying levels of extraversion and the conceptual layer accommodating introversion. But, as noted above, personality tendencies are relatively stable, although they may be expressed differently in different environments. Thus the connectivist imperative of "sharing" and "interactivity" may excite some who are also most likely to share this excitement in an overt way, while the same processes may be a burden to others.

Studies in this area are limited and somewhat inconclusive. Topi, Valacich, and Rao (2002) conducted a small study, which showed that while extraverts found more satisfaction in both face-to-face and computer-mediated communicative environments, introverts were equally able to influence problem-solving outcomes. Jung, Lee, and Karsten (2011) found 
"significant performance differences between extravert-CMG [computer-mediated groups] and introvert-CMG regarding producing unique and diverse ideas," with extraverts performing better in moderate and high idea stimuli environments.

Additionally, the trait of extraversion has been split into two components: sociability-gregariousness and confidence-assertiveness. Feist (2010) refines Topi, Valacich, and Rao's findings, noting that highly creative individuals tend toward the second component and "are generally not sociable and outgoing, but they are independent, confident, and assertive..." (p. 121).

In terms of understanding these personality preferences in learning environments (which would include MOOCs), Puccio (1999) notes:

One warning for instructors is not to automatically assume that only those students who show extraverted tendencies are engaged in the course. Although the introvert does not show overt involvement in course content, this does not mean he or she is not engaged. To the contrary, it may be the more introverted students who are internally stimulated by the concepts presented in a course who are actually the most engaged.

\section{Privacy, Solitude, and Control}

The traits of extraversion and introversion may have implications for "social learning" as a whole since while extraverts can thrive on sociality, introverts crave solitude and often desire privacy. This raises questions about power and personal control in networked learning. Malmud Smith (1997) notes: "The essence of solitude, and all privacy, is a sense of choice and control. You control who watches and learns about you. You choose to leave and return" (p. 37).

The choice of leaving and returning seems on one hand a very viable option in networked learning, with learners variably connecting and disconnecting from networks, both digitally and socially (White \& Le Cornu, 2011). And yet, because of the pace of change and information exchange within networks, this disconnection may well sever people's tacit sense of relatedness and confuse others who seek or expect other rhythms in their connectedness and interactivity. And while much recent work has been devoted to the idea that learning and knowledge creation does not occur in isolation, reflections on privacy and solitude quickly merge into considerations of creativity, a topic not yet considered in depth in relation to connectivism. For example, Storr (1988) notes that in a search for coherence (a word quite relevant in discussions of information abundance), "creators... are able to define identity and achieve self-realization by self-reference; that is, by interacting with their own past work rather than by interacting with other people" (p. 147). This is not necessarily contradictory to some elements of connective and social learning as this "past work" may include ideas compiled from many sources. A concern arises, however, if all (valid) connectivist learning is viewed as being of transaction, of process, and is measured or evaluated largely 
through the lens of ongoing interactivity, evidenced by externalized activities such as online aggregation, posting, and "feeding forward." In this case, voluntary disconnection (temporary or otherwise) may well be viewed as leading to inadequate learning and judging others' learning processes as insufficient. (Issues surrounding involuntary disconnection are not addressed here.)

The emphasis on connection above all else is an especially critical concern as connectivism and networked learning enter the more formal education realms. Many of these call for assessment and accountability in ways that may reflect the "ghost" of educational control discussed by Doll (2002), whereby, for example, even "personal networks" are required to be displayed and evaluated.

The discussion regarding these issues here is relatively brief. The apparent paradox of simultaneously pursuing connectedness and interactivity while at the same time offering the potential to support the individual and that which is "personal" is an aspect of connective learning theory that has not been fully explored.

\section{Exploring Diversity}

The concept of diversity in education is traditionally understood in the light of measurably obvious differences among learners, especially based on gender, race, culture, socioeconomic status and perhaps aptitudes such as Gardner's "intelligences" (Gardner, 1999). Additionally, Baym (2010) notes diversity in the degrees and kinds of interactivity offered by various modes of digital communication, a point relevant to MOOCs.

In connectivism terms, Downes (2010a) shares his understanding of diversity as follows:

....the system of education and educational resources should be structured so as to maximize diversity. The intent and design of such a system should not be to in some way make everybody the same, but rather to foster creativity and diversity among its members, so that each person in a society instantiates, and represents, a unique perspective, based on personal experience and insight, constituting a valuable contribution to the whole.

In the context of this discussion, connectivism's potential ability to support diversity in a significant area of self-motivation, competence, as well as the ability to accommodate diversity on the personality trait spectrum of conscientiousness, offers a unique strength. At the same time, efforts to create structure or requirements within connective learning, which could negatively affect learner choice and autonomy, may hinder diversity. And the complex nature of connective learning, which at this time requires high levels of competence in certain skill areas, and, perhaps, high levels of conscientiousness in contributing to visible participation, means that diversity among connective learners may actually be limited from the outset. 


\section{Competence}

In terms of self-determination theory, the factor of competence is defined as feeling effective in interactions and having the opportunities to enact this effectiveness. A sense of competence is one factor which empowers individuals to further endeavors. In MOOCs, this sense of competence can be affected by many things, including language ability, overall learning and technology skill level, and the ease of user interface and connection.

Connectivism learning advocates have generally supported diversity of expression, including the choice of tools for expression, where learners may gravitate towards those where they feel most competent. However, varying expressions of areas of competence may also create tensions during interaction among learners with diverse formal and informal learning expectations. Puccio (1999), for example, notes that instructors' personal orientations have an "unconscious influence... on expectations of what constitutes productive student behavior."

In terms of connective learning, unconscious influences may also affect expectations in peer-to-peer learning and networked interactions, where individuals may advocate for forum participation over blogging, for example. In some cases these expectations may also include what has been termed a "product bias," in which learners' tangible products (expansive verbal interaction or production of text, for example) are considered a stronger contribution or more valuable to interactivity than less-documentable explorations of potential and process (Beghetto, 2010, p. 456). These issues reinforce the importance of diversity in connective learning, whereby learners may opt for favored (strengths-based) forms of expression and tools which reflect and support their sense of competence.

\section{Conscientiousness}

In considering diversity in light of visible and active $\mathrm{MOOC}$ participants, one speculation is that the most obviously active MOOC participants are individuals high in the psychological trait of conscientiousness, geared toward duty and achievement, perhaps in forms generally rewarded in formal learning environments. (Research by Kirwan, Lounsbury, \& Gibson, 2010 uses a similar understanding of this definition.) For example, regular attendance at MOOC sessions, consistent (public) writing, and public collegial exchanges contribute to an overall perception of active connective learning. MOOCs, which point to such conscientious activities as the most appropriate learning processes, may appeal to these outwardly attentive and active learners more than those less oriented toward these forms of achievement and interaction.

At the same time, there would seem to be ample room in MOOCs for more spontaneous behaviour, a characteristic of the other end of the conscientiousness spectrum, especially in light of the recognition of emergence, although much remains unexplored in this speculation. To date, one example of (possibly) more spontaneous behaviour was negatively perceived by some as violating community or personal boundaries: Stephen Downes' autosubscribing participants to a forum in the CCKo8 MOOC (Mak, Williams, \& Mackness, 2010). 


\section{Exploring Openness}

Connectivist environments to date have framed openness largely in the context of sharing resources, ideas and expertise, and communicating and creating new information and insights through networks. In contrast to the educational traditions of closed lectures, proprietary texts, and classroom-enclosed discussions, openness as sharing in networks offers a refreshing change in perspective and is essential as a tenet of connective learning. Downes (2010a) has described the principle of openness in connective learning as follows:

Openness - the system of education and educational resources should be structured so as to maximize openness. People should be able to freely enter and leave the system, and there ought to be a free flow of ideas and artifacts within the system. This is not to preclude the possibility of privacy, not to preclude the possibility that groups may wish to set themselves apart from the whole; openness works both ways, and one ought to be able to opt out as well as in. But it is rather to say that the structure of the system does not impede openness, and that people are not by some barrier shut out from the system as a whole.

This notably parallels our discussion of connectedness and personal control, above, with an acceptance of entering and leaving the system. This systemic and structural openness is, as noted, perhaps the most significant departure from previous learning theories. Paradoxically, the "sharing" aspects of openness may actually be supported by less personal connectedness in ways that have implications for understanding the "opting out" and "opting in" and inclination for privacy in such environments. Malmud Smith (1997) notes this rather paradoxical relationship between privacy, self-expression, and openness in terms of both sharing and reflective experience: "Whereas on first glance we might think of the wish for privacy as only a wish for aloneness, in fact one of its most important attributes is that it makes possible a deeper, more chosen openness...” (p. 8).

This perspective reinforces Downes' understanding of how privacy and groups may be set "apart," even under the idea of openness (2010a). While some may view the greatest obstacle in MOOCs as the lack of generous and "open" engagement, it is also possible that any "tyranny of participation" (Ferreday \& Hodgson, 2008) may deter those individuals who favour reflection, privacy, and solitude over connectedness and interactivity. At the same time, it is important to emphasize that the idea of privacy does not preclude the idea of sharing, but it may have implications for the pace and extent of openness in connective terms.

The concept of psychological openness infers an internal state rather than an external expression or action. In a psychological context, openness is defined as "the breadth, depth, originality and complexity of an individual's mental and experiential life" (John, Naumann, 
\& Soto, 2008, p. 120). In writing on the role of openness in self-determination, Hodgins and Knee (2002) use and expand on openness as a factor in personality and autonomy:

By "openness" we mean a readiness to perceive ongoing experience accurately, without distorting or attempting to avoid the experience, and a willingness to assimilate novel experiences into self-structures. Another way of stating this is that when individuals function autonomously, they are open to experience what is occurring in the current moment. This openness is similar to what has been called "mindfulness" in both Buddhist writings ....and empirical psychology ... It also relates to the personality dimension of openness ... and to Roger's (1961) suggestion that a fully functioning person is able to encounter experience honestly. (p. 88)

This inner state of openness offers a significantly expanded perspective from the much more externalized "sharing" definition of openness and the "no barriers" definition currently articulated in connectivism. It leaves room for the speculation, for example, that legitimate peripheral participants may be experiencing "openness" in relation to connective learning by being attentive in a mindful and non-judgmental way.

An understanding of psychological openness and its relationship to connectivist principles and process also introduces a potential connection between creativity and connective learning. The personality trait of openness to experience is linked to curiosity, exploration, creativity, and unusual ideas. These elements may be significant in gaining insight into MOOC "early adopters" and in understanding the challenges and rewards of promoting and conducting such unusual learning ventures. By the same token, learners who express discomfort in learning networked environments, calling, for example, for more structure, may be closer to the "more cautious" end of the openness spectrum, with greater preference toward the familiar, including learning conventions and traditions. Questions remain as to how connective learning can best accommodate learners throughout this spectrum.

\section{Discussion}

While elements related to the psychological diversity of learners have at least tacitly been acknowledged as a backdrop in learning, learning systems or theories have generally been limited in their ability to accommodate or be actively responsive to the highly and potentially variable complex interactions among psychologically diverse individuals. (Attempts to do so generally utilize the Myers-Briggs Type Indicator.) A potential strength of connectivism as a learning theory lies in the potential ability (and perhaps need) for (healthy) networks to accommodate the psychological diversity of participating individuals.

Sawyer (2010, p. 366) suggests that the idea of collaborative emergence best explains how 
new things are created, in which both individual and collective explanation are incorporated. We find parallels in the suggestion that attention to principles of connectivism in relation to both networks and the individual may be beneficial in the further development of connective learning.

An understanding of the complexity of social, conceptual, and biological connections along with the complexity of human needs and the diverse circumstances generating and emerging from these connections is an emerging process for connectivist understanding. Without this augmented recognition, there is the risk that connectivism will serve as another educational prescription or as a description of information and knowledge flow, rather than a theory of learning and a conduit for growth and even transformation (Mezirow, 2000), which may also be inferred in Downes' recognition of "learning to become" (2011). As Wenger (2011) notes: "Learning is not merely the acquisition of a body of knowledge, but $a$ journey of the self" (Authors' italic). (At the same time, this view itself may be a product of psychological diversity in terms of intrinsic motivation. For example, Feist (2010, p. 122) theorizes: "Scientists are probably more driven by the need to know and artists more by the need for self-expression.”)

Understanding the psychological dimensions or interpretations of connectivist principles also suggests that participation variables in testing environments such as MOOCs and distance learning courses might not in all cases be the result of the ability or inability to cope with the diverse learning environments and choice and control requirements of autonomous learning, but, rather, forms of individual self-expression. A paradox here is that acknowledging and accepting the importance of individual and psychological diversity, autonomy, connectedness, and openness may well result in some learners choosing (in appearance or actuality) very limited engagement with networked learning environments such as MOOCs.

Additionally, the exploration of self-determination theory and personality theory in connectivist and MOOC landscapes has implications for expectations of people's learning in online learning and open networks. In particular, efforts to marginalize the significance of individuals or efforts to seek conclusive or limiting definitions and roles for individuals within connectivist theory are potentially, and perhaps ironically, counterproductive to the furtherance of connectivist learning. This is potentially as applicable for MOOC conveners and connectivism facilitators as it is for MOOC "learners" (while recognizing that connectivism suggests these are not distinct roles). While there have been calls for more or different efforts on the part of MOOC facilitators (Dron, 2011), the psychological insight brought by contemporary personality theory and self-determination theory suggests that the manipulation or envisioned refinement of MOOC environments and processes may be moot, or certainly less effective than it is typically assumed to be in the promotion of learning and curriculum design. Indeed, in their exploration of self-direction and personality in college students, Kirwan, Loundsbury, and Gibson (2010) conclude with a parallel consideration: "It may be that personality traits, not academic and personal experiences, are the major determinants of college student self-direction in learning."

If the idea that learning experiences (and, by association, perhaps their facilitation) are less 
influential for learning than personality traits, there may be benefits to increased attention to the role of self-determination and personality. This also raises the question as to whether connectivism, with attention to the existing and newly proposed dimensions of autonomy, connectedness, diversity, and openness offered here, is primed to step (or remain) beyond more traditional views of how learning occurs and is best enabled. Connectivism may offer a framework in which the focus on the primarily external structures, processes, and demands of learning (which even in contemporary execution could be regarded as vestiges of behaviorism) is reduced, and factors which address and accept how learners engage and motivate the self in the development of personal potential come to the fore. It is in the context and recognition of this engagement of the self that we find connectivism is a prescient and viable framework for learning, offering great potential ...but also offering paradoxes and uncertainty during transitional times in the understanding, acceptance, and incorporation of these ideas.

As understanding of connectivism increases and as connectivism's principles are put to the test in our daily learning, we hope to see a recognition of network capabilities and possibilities intertwined with the recognition of human concerns and potential in a networked and connectivist world. 


\section{References}

Anderson, T., \& Dron, J. (2011). Three generations of distance education pedagogy. International Review of Research in Open and Distance Learning. Retrieved from http://www.irrodl.org/index.php/irrodl/article/view/89o

Aviram, A., \& Assor, A. (2010). In defense of personal autonomy as a fundamental educational aim in liberal democracies: A response to Hand. Oxford Review of Education, 36(1), p. 111-126.

Baym, N.K. (2010). Personal connections in the digital age. Digital Media and Society Series. Polity Press.

Beghetto, R.A. (2010). Creativity in the classroom. In Kaufman, J. C. \& Sternberg, R.J., The Cambridge handbook of creativity. Cambridge University Press.

Bell, F. (2011). Connectivism: Its place in theory-informed research and innovation in technology-enabled learning. The International Review of Research in Open and Distance Learning. Retrieved from: http://www.irrodl.org/index.php/irrodl/article/ view/902

Bouchard, P. (2011). Network promises and their implications. In The impact of social networks on teaching \& learning (online monograph). Revista de Universidad y Sociedad del Conocimiento (RUSC), 8(1), 288-302. University of Catalunya. Retrieved from http://rusc.uoc.edu/ojs/index.php/rusc/article/view/v8n1-bouchard/v8n1-bouchard-eng

Cormier, D. (2011) Ple diagrams. Retrieved from: http://edtechpost.wikispaces.com/ $\underline{\text { Ple+Diagrams }}$

Crome, K., Farrar, R., \& O'Connor, P. (2011). What is autonomous learning ? The role of autonomous learning in higher education. Discourse, 9(1), p.111-126. Retrieved from http://www.prs.heacademy.ac.uk/pdf.html/PrsDiscourseArticles/113

Dron, J. (2007). Control and constraint in e-learning: choosing when to choose. Idea Group Publishing. Retrieved from http://bit.ly/iP9ah9

Dron, J. (2011) And so it ends... Retrieved from https://landing.athabascau.ca/pg/blog/ $\underline{\mathrm{read} / 91481 / \mathrm{and}-\mathrm{so}-\mathrm{it}-\mathrm{ends}}$

Doll, W. E. Jr. (2002). Ghosts and the curriculum. In Doll, W. E. Jr. \& Gough, N. (Eds.) Curriculum visions. New York, Washington DC/Baltimore: Peter Lang.

Downes, S. (2005). An introduction to connective knowledge. Retrieved from http://www. downes.ca/post/33034

Downes, S. (2007). What connectivism is. Retrieved from http://halfanhour.blogspot. 
com/2007/02/what-connectivism-is.html

Downes, S. (2010a). What is democracy in education? Retrieved from http://halfanhour. blogspot.com/2010/10/what-is-democracy-in-education.html

Downes, S. (2010b). A model of autonomy. Retrieved from http://halfanhour.blogspot. com/2010/11/model-of-autonomy.html

Downes, S. (2011). Identity and learning. Retrieved from http://www.downes.ca/archive/11/09 26 news OLDaily.htm

Feist, G. J. (2010). The function of personality in creativity. In Kaufman, J. C. \& Sternberg, R.J., The Cambridge handbook of creativity. Cambridge University Press.

Ferreday, D. J., \& Hodgson, V.E. (2008). The tyranny of participation and collaborating in networked learning. 6th International Networked Learning Conference, Halkidiki, Greece.

Gardner, H. (1999). Intelligence reframed. Multiple intelligences for the 21st century. New York: Basic Books.

Hodgins, H.S., \& Knee, C.R. (2002). The integrating self and conscious experience. In Deci, R.M. \& Ryan, R.M. (Eds.), The handbook of self-determination research. The University of Rochester Press.

John, O.P., Naumann, L.P., \& Soto, C.J. (2008). Paradigm shift to the integrative Big Five trait taxonomy. In John, O.P., Robins, R.W. \& Pervin, L.A. (Eds). Personality handbook: Theory and research (p. 114-158). New York: Guilford.

John, O.P., \& Srivastava, S. (1999). The big-five trait taxonomy: History, measurement, and theoretical perspectives. Retrieved from http://pages.uoregon.edu/sanjay/ pubs/bigfive.pdf

Jung, J. H., Lee, Y., \& Karsten, R. (2011). The moderating effect of extraversion-introversion differences on groupideageneration performance.Small Group Research. Retrieved from http://sgr.sagepub.com/content/early/2011/o9/20/1046496411422130

Kirwan, J.R., Lounsbury, J.W., \& Gibson, L.W. (2010) Self-direction in learning and personality: The big five and narrow personality traits in relation to learner self-direction. International Journal of Self-Directed Learning, 7(2), 21-34.

Kop, R. (2011). The challenges to connectivist learning on open online networks: Learning experiences during a massive open online course. International Review of Research in Open and Distance Learning. Retrieved from http://www.irrodl.org/ index.php/irrodl/article/view/882

Kop, R., \& Fournier, H. (2010). New directions to self-directed learning in open networked 
learning. International Journal of Self-Directed Learning, 7(2), p. 1-20.

Kop, R., \& Hill, A. (2008) Connectivism: Learning theory of the future or vestige of the past. International Review of Research in Open and Distance Learning. Retrieved from http://www.irrodl.org/index.php/irrodl/article/view/523/

Mackness, J., Mak, Sui, Fai, J., \& Williams, R. (2010). The ideals and reality of participating in a MOOC. In Networked Learning Conference, Aarlborg (pp. 266-274). Retrieved from http://www.lancs.ac.uk/fss/organisations/netlc/past/nlc2010/ abstracts/Mackness.html

Mak, Sui, Fai, J., Williams, R., \& Mackness, J. (2010). Blogs and forums as communication and Learning tools in a MOOC. In Networked Learning Conference, Aarlborg (p. 275-284). Retrieved from http://www.lancs.ac.uk/fss/organisations/netlc/past/ nlc2010/abstracts/Mak.html

Malmud Smith, J. (1997). Private matters: In defense of the personal life. Reading, Massachusetts: Addison Wesley

McCrae, R.R., \& Costa, P.T. (1987). Validation of the five-factor model of personality across instruments and observers. Journal of Personality and Social Psychology, 52, 8190 .

Mezirow, J. (2000). Learning as transformation. San Francisco: Jossey Bass.

Puccio, G.J. (1999). Psychological diversity: Implications for teaching and learning. Retrieved from http://www.buffalostate.edu/orgs/cbir/readingroom/html/Puccio-99.html

Ryan, R.M., \& Deci, E.L. (2002). An overview of self-determination theory: An organismicdialectical perspective. In Deci, R.M. \& Ryan, R.M. (Eds.), The handbook of selfdetermination research. The University of Rochester Press.

Sawyer, R. K. (2007). Group genius: The creative power of collaboration. New York: Basic Books.

Sawyer, R. K. (2010). Individual and group creativity. In Kaufman, J. C. \& Sternberg, R.J., The Cambridge handbook of creativity. Cambridge University Press.

Siemens, G. (2004). Connectivism. A learning theory for the digital age. Retrieved from http://www.elearnspace.org/Articles/connectivism.htm

Siemens, G. (2006). Learning theory or pastime for the self-amused? Retrieved from http:// www.elearnspace.org/Articles/connectivism self-amused.htm

Siemens, G. (2008). What is the unique idea in connectivism. Retrieved from http://www. connectivism.ca/?p=116 
Siemens, G. (2010). My personal learning network is the most awesome thing ever. Retrieved from http://www.elearnspace.org/blog/2010/12/01/my-personal-learning-network-is-the-most-awesomest-thing-ever/

Siemens, G. (2011). Moving beyond self-directed learning: Network-directed learning. Retrieved from http://www.connectivism.ca/?p=307

Storr, A. (1988). Solitude. A return to the self. New York. Free Press.

Thanasoulas, D. (2002). What is learner autonomy and how can it be fostered? Retrieved from http://www3.telus.net/linguisticsissues/learnerautonomy.html

Topi, H., Valacich, J., \& Rao, M.T. (2002). The effects of personality and media differences on the performance of dyads addressing a cognitive conflict task. Small Group Research, 33, 667. Retrieved from http://sgr.sagepub.com/content/33/6/667.short

Verhagen, P. (2006). Connectivism: A new learning theory? Retrieved from http://www.4shared. com/office/ddZv-naA/Connectivism a new learning th.html

Wellman, B., \& Gulia, M., (1998). Net surfers don't ride alone: Virtual community as community. In Kollock, P., \& Smith, M. (Eds.), Communities in cyberspace (pp. 167195). Berkley: University of California Press.

Wenger, E. (2011). Learning in and across landscapes of practice. Lancaster University, UK. Retrieved from http://www.lancs.ac.uk/celt/celtweb/ewenger

White, D.S. \& Le Cornu, A. (2011) Visitors and residents: A new typology for online engagement. First Monday, 16(9). Retrieved from http://firstmonday.org/htbin/ cgiwrap/bin/ojs/index.php/fm/article/view/3171/3049

\section{Athabasca University $\mathbf{I}$}

